\title{
Pre-malignant lymphoid cells arise from hematopoietic stem/progenitor cells in chronic lymphocytic leukemia
}

\author{
Yoshikane Kikushige • Toshihiro Miyamoto
}

Received: 5 November 2014 / Revised: 8 January 2015 / Accepted: 15 January 2015 / Published online: 3 February 2015

(c) The Japanese Society of Hematology 2015

\begin{abstract}
Human malignancies progress through a multistep process that includes the development of critical somatic mutations over the clinical course. Recent novel findings have indicated that hematopoietic stem cells (HSCs), which have the potential to self-renew and differentiate into multilineage hematopoietic cells, are an important cellular target for the accumulation of critical somatic mutations in hematological malignancies and play a central role in myeloid malignancy development. In contrast to myeloid malignancies, mature lymphoid malignancies, such as chronic lymphocytic leukemia (CLL), are thought to originate directly from differentiated mature lymphocytes; however, recent compelling data have shown that primitive HSCs and hematopoietic progenitor cells contribute to the pathogenesis of mature lymphoid malignancies. Several representative mutations of hematological malignancies have been identified within the HSCs of CLL and lymphoma patients, indicating that the self-renewing long-lived fraction of HSCs can serve as a reservoir for the development of oncogenic events. Novel mice models have been established as human mature lymphoma models, in which specific oncogenic events target the HSCs and immature progenitor cells. These data collectively suggest that HSCs can be the cellular target involved in the accumulation of oncogenic events in the pathogenesis of mature lymphoid and myeloid malignancies.
\end{abstract}

\footnotetext{
Y. Kikushige $\cdot$ T. Miyamoto $(\square)$

Department of Medicine and Biosystemic Sciences, Kyushu University Graduate School of Medicine, 3-1-1 Maidashi, Higashi-Ku, Fukuoka 812-8582, Japan

e-mail: toshmiya@intmed1.med.kyushu-u.ac.jp

Y. Kikushige

Japan Society for the Promotion of Science, Tokyo, Japan
}

Keywords Hematopoietic stem cell $\cdot$ Chronic lymphocytic leukemia $\cdot$ Pre-leukemia/pre-lymphoma

\section{Introduction}

Malignant transformation often occurs through a multistep process that includes the development of critical somatic mutations. Recent advanced technologies including next-generation sequencing (NGS) analysis have enabled us to identify recurrent somatic mutations in many hematological malignancies including leukemias and lymphomas [1-19]. Using clonological analysis of patient samples, it has been shown that clonal evolution via additional key mutations frequently leads to a growth advantage in malignant cells. It is important to note that only cells with a long lifespan can accumulate these mutations, and in hematopoiesis, the self-renewing hematopoietic stem cells (HSCs) are one of the critical cellular targets that can amass multiple genetic abnormalities. HSCs with multiple genetic abnormalities can produce a number of myeloid or lymphoid progenitors that have identical abnormalities, and these progenitors are the final target for the transformation into leukemic stem cells (LSCs) in acute leukemia [20] (Fig. 1).

These models for LSC development have been directly shown in human myeloid malignancies. In chronic myelogenous leukemia (CML), BCR-ABL fusion resulting from $t(9 ; 22)$ can develop into HSCs to form the chronic phase of this disease, but during myeloid blast crisis, additional genetic abnormalities can transform granulocyte/macrophage progenitors (GMPs) into LSCs. In $t(8 ; 21)$ AML, the AML1-ETO fusion is found in HSCs; however, these $\mathrm{AML}-\mathrm{ETO}^{+}$HSCs can differentiate into mature blood 


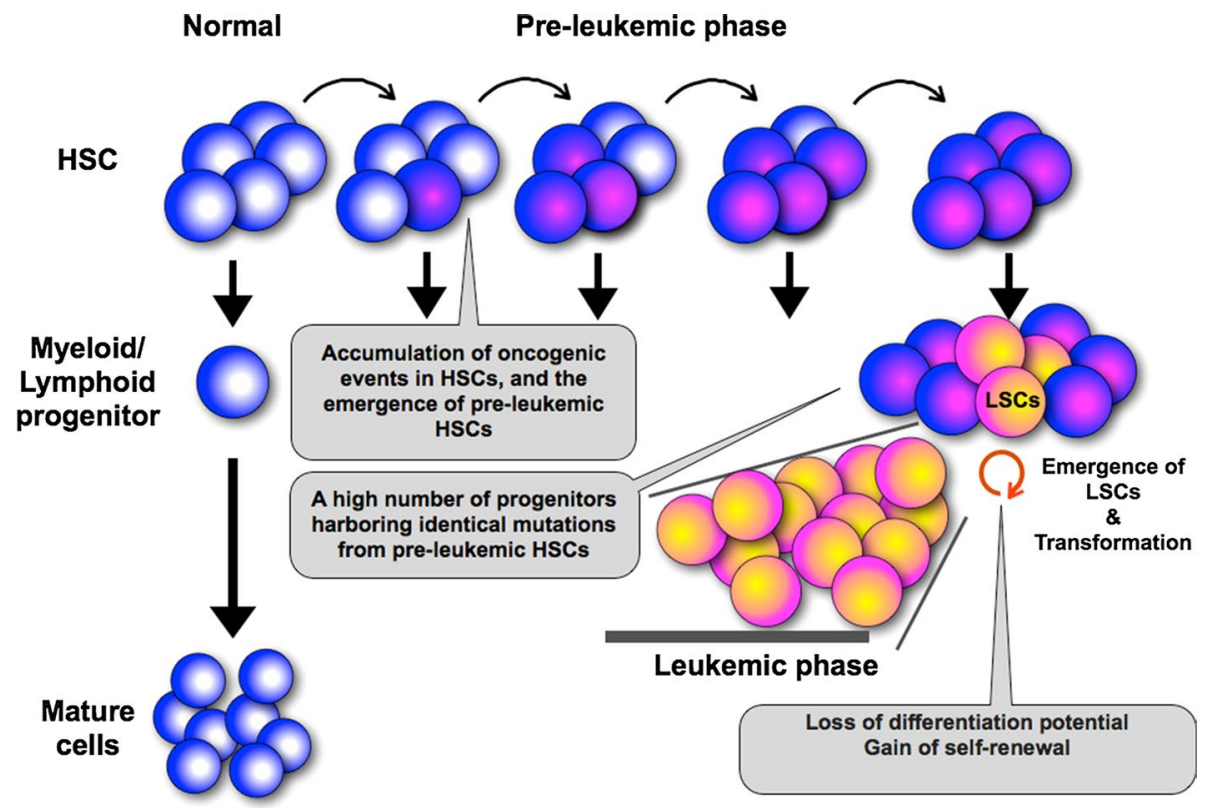

Fig. 1 Schematic representation of the emergence of LSCs in human acute leukemia. Accumulation of oncogenic events occur in selfrenewing HSCs and leads to the emergence of aberrant pre-leukemic HSCs. These aberrant pre-leukemic HSCs self-renew and expand within HSC fraction. Pre-leukemic HSCs give rise to a high number of lineage-committed progenitors harboring the identical mutations. It leads to the increased chances of acquiring the additional oncogenic

cells [21, 22]. Additional mutations such as c-KIT mutations are critical for the formation of AML LSCs at the GMP stage [23]. Furthermore, NGS analyses have shown that pre-malignant clones carrying somatic mutations have been frequently found in HSCs of patients with AML without specific chromosomal abnormalities [24, 25]. It has also been shown that the number of acquired somatic mutations in HSCs increases with age [26]. Thus, self-renewing HSCs are a reservoir for mutations at least in myeloid malignancies [27].

In contrast, the involvement of HSCs had not been considered in lymphoid malignancies until recently. However, we have reported that in mature lymphoid malignancies, such as chronic lymphocytic leukemia (CLL), the cellular propensity for clonal B cell development has been achieved at the HSC level [28, 29]. It has also been reported that the genetic alterations specific for $\mathrm{T}$ cell lymphoma [30, 31], follicular lymphoma (FL) [32], and hairy cell leukemia $(\mathrm{HCl})$ [33] could be traced up to the HSC stage. These studies have suggested that even in relatively mature lymphoid malignancies, human HSCs could be a reservoir for genetic mutations, which constitutes a prime source for leukemia/lymphoma development. This review summarizes recent data regarding the involvement of HSCs and the presence of pre-malignant state in mature lymphoid malignancies. events, which finally transform the aberrant progenitor cells from preleukemic HSCs into the leukemic stem cells (LSCs). Loss of the differentiation potential and gain of self-renewing potential are essential for the emergence of LSCs. These sequential leukemia progression models are commonly accepted in the development process of human myeloid malignancies

\section{Chronic lymphocytic leukemia}

CLL is a mature $\mathrm{B}$ cell malignancy characterized by the accumulation of clonal mature $\mathrm{CD}^{+} \mathrm{B}$ cells in the blood, bone marrow, and lymphoid tissues [34, 35]. The prevalence of CLL increases dramatically with age. Human CLL cells express functional $\mathrm{B}$ cell receptors (BCRs) on their cell surfaces as a result of productive immunoglobulin gene rearrangement [34, 36, 37]. CLL cases can be divided into two subgroups based on the presence or absence of somatic hypermutations within the variable regions of the immunoglobulin heavy chain (IGH) genes. In normal B cell development, the somatic hypermutations occur in the germinal centers during the naïve-to-memory B cell transition. CLL patients with mutated BCRs have a better prognosis than those without BCR mutations [38]. Recent transcriptome analysis of human CLL cells has suggested that CLL with unmutated BCRs may be derived from unmutated mature $\mathrm{CD}^{+} \mathrm{B}$ cells, whereas CLL with mutated BCRs may result from a $\mathrm{CD} 5^{+} \mathrm{CD} 27^{+}$post-germinal center $\mathrm{B}$ cell subset [39].

It is important to note that CLL is not always a monoclonal disorder. Multiple CLL clones were found in $3.4 \%$ of typical CLL patients and in $13.8 \%$ of atypical CLL patients [40]. Overall, $4.8 \%$ of 477 consecutive CLL cases had two or more clonal B cell populations [40]. Furthermore, 
a large cohort study demonstrated that 44 out of 45 CLL patients exhibited a precursor state such as monoclonal B lymphopoiesis (MBL) for 6 months to 7 years [41]. Thus, MBL should be considered as a pre-leukemic state for CLL, characterized by the asymptomatic proliferation of circulating B cells $(<5,000 / \mu \mathrm{L})$ [42]. Of note, human MBL sometimes involves multiple B cell clones [43-46]. The prevalence of MBL increases with age [41, 47]. Most MBL clones exhibit an immunophenotype similar to that of CLL [48] and develop into CLL at an estimated annual rate of $1.1-1.4 \%[47,49]$.

When considering the pathogenesis of CLL, it is important to know that BCR signaling can play a critical role in the development of CLL. CLL cells can express a restricted BCR repertoire including antibodies with quasi-identical CDR3 [50-53]. The striking degree of structural restriction of BCR in CLL suggests that common or similar antigens are recognized by CLL cells, and supports the hypothesis that an antigen-driven selection process contributes to CLL pathogenesis [35]. Such antigens may include autoantigens, partly because CLL cells express autoreactive and polyreactive BCRs [54-57], indicating that CLL cells originate from self-reactive B cell precursors [57].

Evidence that HSCs involve in the pathogenesis of human CLL based on a xenograft model

The existence of oligoclonal B cell clones in both CLL and MBL cases supports the idea that the first oncogenic event may be traced back to a progenitor or self-renewing HSC or early progenitor cells prior to IGH gene rearrangement.

\section{CLL patients had increased number of proB cells}

If the pathogenesis of CLL involves strictly mature B cells, the number of cells at the stem or progenitor stage should not be affected. However, in CLL patients, the percentages of $\mathrm{CD} 34^{+} \mathrm{CD} 38^{+}$and $\mathrm{CD} 10^{+} \mathrm{CD} 19^{+}$proB cells were significantly (approximately five-fold) higher than those of normal controls, whereas the percentage of $\mathrm{CD} 34^{+} \mathrm{CD} 38^{-}$ HSCs was not different [28]. Importantly, these increased proB cells had polyclonal IGH rearrangements, suggesting that the HSCs in CLL patients are intrinsically skewed toward a B cell lineage commitment, and are capable of producing higher numbers of proB cells.

\section{Mice engrafted with HSCs from CLL patients developed a high number of proB cells and oligoclonal mature B cells}

Xenograft models utilizing immunodeficient mice have been used to identify leukemia-initiating cells [58]. However, human CLL had never been efficiently reconstituted by the transplantation of whole or fractionated circulating
CLL cells, which has interfered with the understanding of the pathogenesis of this disease. We have recently reported that CLL-like disease can be reconstituted in mice by xenotransplantation of HSCs from CLL patients [28].

In our study, the blood or bone marrow CLL cells were not engrafted in immunodeficient mice, but the purified $\mathrm{CD} 34^{+} \mathrm{CD} 38^{-}$HSCs from the bone marrow of CLL patients could reconstitute multilineage hematopoiesis over the long term. The lineage readout of HSCs from CLL patients (CLL-HSCs), however, was different from that of normal HSCs. First, the percentage of human proB cells was significantly higher in mice reconstituted with CLLHSCs than those with normal HSCs. Second, CLL-HSCs produced higher numbers of human $\mathrm{B}$ cells than normal HSCs, and these B cells contained a considerable amount of $\mathrm{CD}^{+} \mathrm{B}$ cells, suggesting that the development of HSCs in CLL patients was skewed toward the B lymphoid lineage as seen in the patients' bone marrow. Third, mature B cells that developed from CLL-HSCs had either a monoclonal or oligoclonal IGH rearrangement; both of these patterns were independent of those contained in their original CLL clones [28]. Thus, the propensity to generate clonal B cells has already been acquired at the HSC stage in CLL patients.

\section{CLL-HSCs had expression signatures skewed into the lymphoid lineage}

The fact that the CLL-HSCs generate a high number of proB cells and produce monoclonal or oligoclonal mature $\mathrm{B}$ cell populations in vivo strongly suggests that the CLLHSCs possess cell-intrinsic abnormalities to enable the cells to exhibit this phenotype. It has been shown that lineage-associated genes were expressed at a low level prior to the lineage commitment (lineage priming) [59, 60]. Single-cell gene expression assays of CLL-HSCs showed that a considerable fraction of CLL-HSCs had started to transcribe early lymphoid transcription factors such as IKZFI, $E 2 A$, and $I R F 8$, but had not transcribed the late lymphoid or myeloerythroid transcription factors [28].

From these data, we concluded that HSCs were involved in the pathogenesis of human CLL, presumably serving as aberrant pre-leukemic HSCs (Fig. 2). Normal HSCs always gave rise to polyclonal $\mathrm{B}$ cell populations, whereas the transplanted CLL-HSCs gave rise to abnormally expanded monoclonal or oligoclonal mature B cell populations in vivo. These data indicated that the propensity to generate clonal B cells had already been acquired at the HSC stage in CLL patients. CLL-HSCs can produce an increased number of polyclonal proB cells. Their mature B cell progeny should be positively selected by autoantigen(s), resulting in abnormal monoclonal or oligoclonal expanded $\mathrm{B}$ cell populations (Fig. 2). Therefore, these B cell clones that were developed in the immunodeficient mice might 
Fig. 2 Schematic representation of human chronic lymphocytic leukemia (CLL) development from HSCs based on xenograft model. Pre-leukemic HSCs carry accumulated genetic or epigenetic abnormalities that may influence skewed $B$ cell differentiation, leading to the production of a high number of polyclonal B cells that carry the identical aberrations. These $\mathrm{B}$ cell clones are selected and expanded in response to $\mathrm{B}$ cell receptor (BCR) signaling. The further accumulation of leukemogenic events should be necessary for the full transformation of monoclonal B cell lymphocytic clones to clinical CLL. Our xenograft model indicated that the aberrant HSCs in CLL patients contribute to the generation of clonally expanded mature B cells

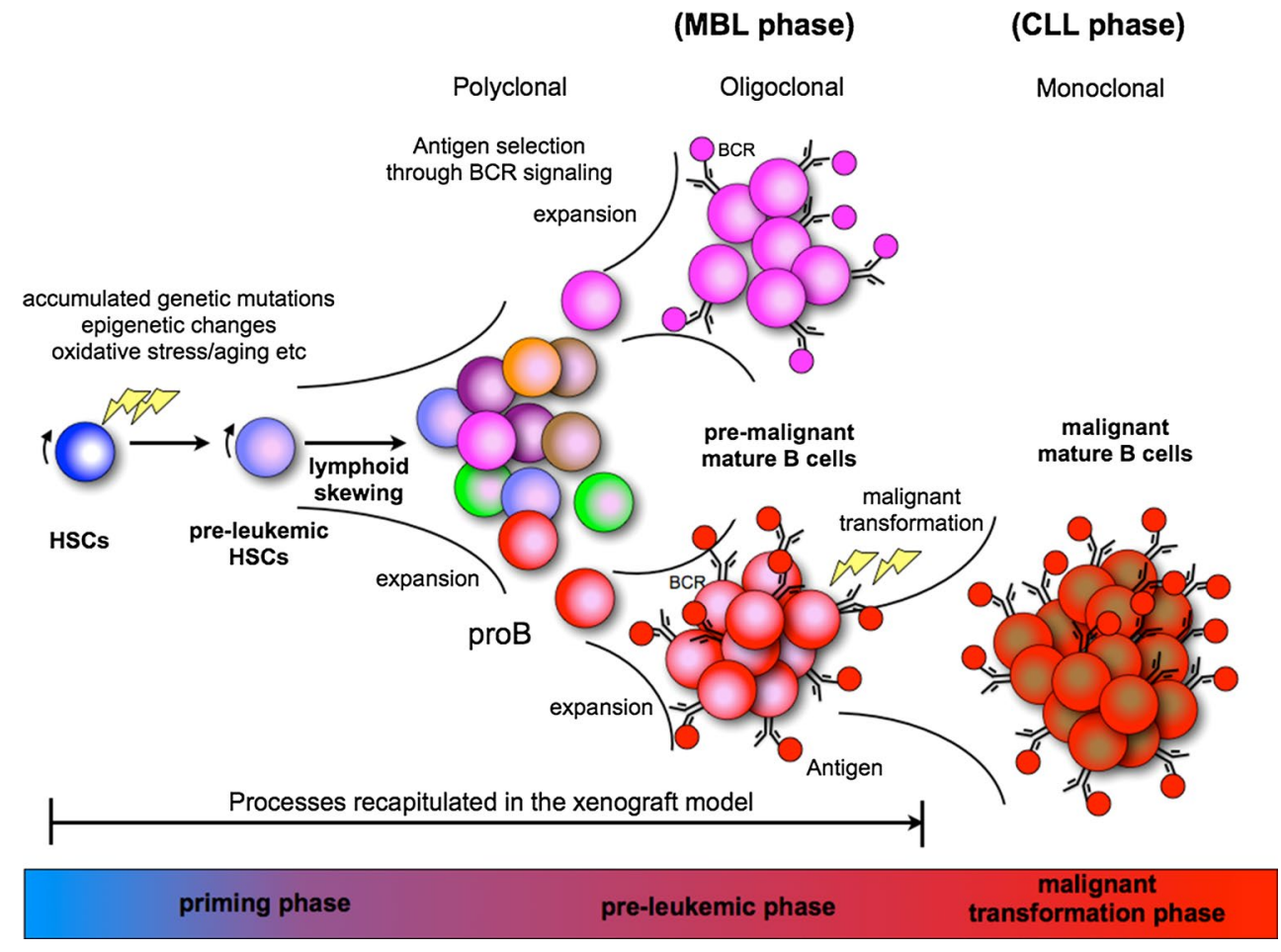

correspond to human MBL, the pre-leukemic state of CLL. These MBL-like B cell clones differed from the original CLL clone in patients, because the $\mathrm{V}(\mathrm{D}) \mathrm{J}$ recombination was completely different, and they did not have the abnormal karyotypes from the original CLL cells. This probably occurred because the MBL-like clones derived from the CLL-HSCs would be selected by mouse antigens, but would not be selected by the human auto-antigens. Therefore, this was not frank CLL, and instead resembled modeling MBL. At some point along the differentiation pathway, additional genomic abnormalities may develop, eventually resulting in the clonal CLL disorder (Fig. 2). If this model does reflect the biology of the in situ human disease, one would expect to detect an oligoclonal disease in both CLL and/or MBL patients. Indeed, this oligoclonality of the $\mathrm{V}(\mathrm{D}) \mathrm{J}$ recombination is relatively common in MBL and is also seen in approximately $10 \%$ of CLL cases.

Our data indicated that the aberrant HSCs in CLL patients can contribute to the generation of clonally expanded mature B cells. These expanded mature B cell clones can serve as a reservoir for the subsequent additional oncogenic events that can lead to the full transformation to clinical CLL in humans. Our hypothesis regarding CLL development has been schematized in Fig. 2.

Acquired genetic alterations in HSCs in CLL patients

The finding of aberrant HSCs in CLL raises the question of what mechanisms drive this process. Presumably, genetic and/or epigenetic mutations are present in these cells and determine their aberrant behavior. Recently, NGS has identified recurrent somatic mutations that presumably drive transformation in CLL [4-6]. It will be of great interest to determine if these mutations are present in the HSCs from CLL patients. A recent study by Damm et al. [61] confirmed the presence of acquired initiating mutations in the early hematopoietic cells of CLL patients. To search for CLL mutations in the hematopoietic stem/progenitor cell (HSPC) fraction, the presence of $S F 3 B 1$ mutations in each hematopoietic lineage was examined because SF3B1 is frequently mutated in both CLL [5, 6] and MDS [3], another HSC-derived myeloid malignancy. Sequencing analyses of DNA from FACS-purified $\mathrm{CD}^{+} \mathrm{T}$ cells, CD $14^{+}$monocytes, CD $19^{+}$CLL cells, and CD34 ${ }^{+} \mathrm{HSPCs}$ showed wild-type $S F 3 B 1$ sequences in the $\mathrm{CD}^{+} \mathrm{T}$ cells and a mutated sequence in the $\mathrm{CD} 19^{+} \mathrm{CLL}$ fraction in the seven $S F 3 B 1$ mutated CLL cases. Conventional capillary sequencing revealed the presence of $S F 3 B 1$ mutations in the $\mathrm{CD} 34^{+} \mathrm{HSPCs}$ and/or the $\mathrm{CD} 14^{+}$fractions in two of the SF3B1-mutated CLL cases, indicating that a significant proportion of the $\mathrm{CD} 34^{+}$HSPCs and/or CD $14^{+}$monocytes harbored SF3BI mutations. The extended analysis using whole-exome sequencing revealed that at least one somatic mutation was detectable in the FACS-purified $\mathrm{CD} 14^{+}$ monocytes and in the $\mathrm{CD}_{3} 4^{+}$immature HSPC fractions in 21 of $24(88 \%)$ CLL patients. Importantly, the mutations detected in the HSPCs of CLL patients affected the genes that were already known to have mutations in CLL and 


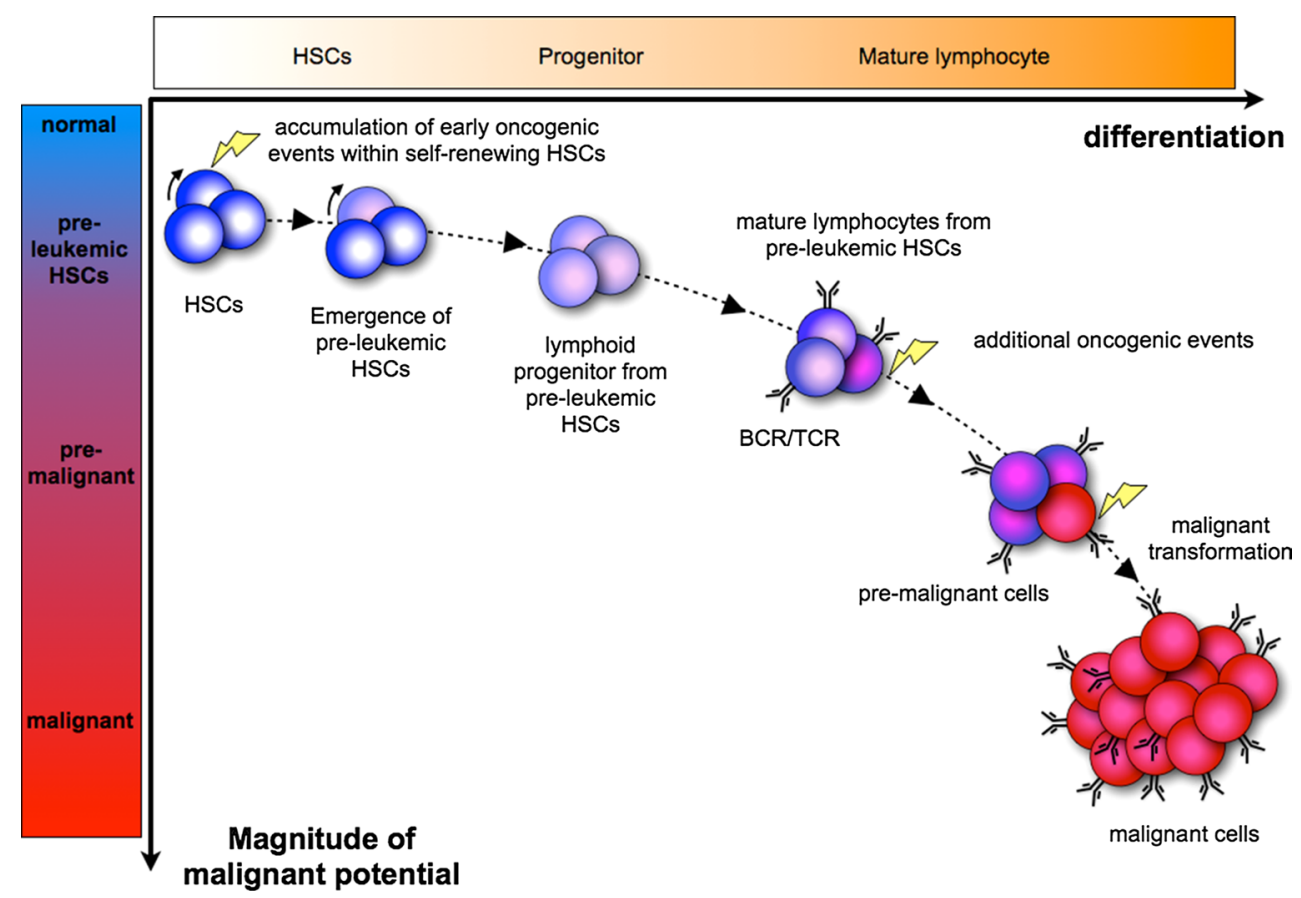

Fig. 3 Schematic representation of novel lymphoid malignancy development model from self-renewing HSCs. The novel mature lymphoid malignancy developmental model; the early oncogenic events occur and accumulate within the self-renewing HSCs. The early oncogenic events acquired within self-renewing HSCs contribute to the emergence of the aberrant pre-leukemic HSCs in a similar manner as myeloid malignancies. The pre-leukemic HSCs can give rise to pre-malignant mature lymphoid cells harboring the identical abnormalities, and these pre-malignant clones may have a growth

other hematological malignancies, or even in other cancers, indicating the active contribution of HSPCs to CLL pathogenesis. The frequencies of these early mutations were investigated using direct Sanger sequencing of the mutational hotspot containing BRAF, EGR2, MED12, MYD88, NFKBIE, NOTCH1, SF3B1, TP53, and XPO1 in 168 CLL patients. Surprisingly, $84 / 168$ (50\%) of CLL patients presented with at least one mutated gene of the nine listed genes that had been detected as early mutations in the study [61]. These observations give us an important insight into the pathogenesis of CLL; the recurrent CLL somatic mutations can be acquired within HSPCs of a majority of CLL patients, indicating that HSPCs should be the cellular target of the early oncogenic events initiated during the multistep process of CLL pathogenesis.

The targeted deep sequencing and single HSPC-derived myeloid colony analysis revealed that the distribution of early somatic mutations seemed to be classified into two patterns according to the lineage-involvement pattern. The first pattern was represented by the cases in which the $\mathrm{CD} 34^{+}$ HSPCs and mature myeloid cells harbored the early somatic mutations at the similar frequencies. This distribution or survival advantage over normal clones, resulting in the increased chances of gaining appropriate oncogenic events at the specific differentiation stages. Additional oncogenic events are required for the malignant transformation or emergence of tumor-initiating cells. This model indicates that the process of lymphomagenesis can be initiated at HSC stage and gradually progress through the pre-malignant phase in humans, rather than the direct malignant transformation from the normal mature lymphoid cells

indicated a "multilineage involvement pattern", in which mutated HSPCs can contribute to normal hematopoiesis including the myeloid lineage in a steady state. The second pattern was represented by the cases in which the $\mathrm{CD} 34^{+}$ HSPCs showed relatively high mutant allele frequencies, but only limited myeloid cells harbored the same mutations. This distribution can be regarded as a "lymphoid-restricted involvement pattern". This lymphoid-restricted involvement pattern implied the presence of an alternative differentiation potential of the mutated HSPCs and suggested that the early oncogenic events could significantly affect the lineage commitment process or the differentiation potential of HSPCs.

Further studies will clarify the precise mechanisms of how these early oncogenic events affect the cellular fate decisions of the hematopoietic progenies derived from the pre-leukemic HSPCs.

\section{Conclusions and perspectives}

The involvement of HSCs in the pathogenesis of mature lymphoid malignancies has been demonstrated by 
functional and genetic analysis [28, 30-33]. HSCs from the patients with mature lymphoid malignancies harbored identical somatic mutations that were detected in the tumor cells, indicating that early oncogenic events could target self-renewing HSCs during the stepwise disease developmental process. Importantly, many of the early somatic mutations acquired within HSCs of the mature lymphoid malignancies were commonly observed in myeloid malignancies as well as various lymphoid malignancies. Indeed, the early oncogenic mutations commonly observed in both myeloid and lymphoid malignancies include $S F 3 B 1, T E T 2$, and $D N M T 3 A$, and the mutations of these genes can affect broad cellular functions through multiple processes such as RNA splicing and epigenetic modification. In addition, the early mutations acquired within HSCs of CLL patients such as BRAF, MLL2, NOTCH1, MYD88, EGR2, XPO1, and KLHL6 were commonly detected in various types of lymphoid malignancies; this indicated that these mutations did not determine the specific disease subtypes. These observations raised the possibility that the early oncogenic events acquired within HSCs contributed to the emergence and maintenance of pre-leukemic HSCs rather than directly inducing specific types of mature lymphoid malignancies. Our hypothesis regarding the mature lymphoid malignancy development model from HSCs is schematized in Fig. 3. This model does not indicate that the tumor-initiating cells exist within the pre-leukemic HSCs but rather suggest that the priming processes that enable the emergence or propagation of pre-malignant lymphoid clones have already been initiated at the stage of HSCs. The presence of pre-malignant lymphoid clones can facilitate lymphomagenesis by increasing the chances of acquiring appropriate oncogenic events within the mature lymphoid cells, whose life span is relatively limited.

In addition to the detailed analysis of primary human samples, the murine models of mature lymphoid malignancies have been successfully established by targeting HSCs; the ectopic expression of disease-specific oncogenes such as BrafV600E, MALT1, MafB, HGAL, and Bcl6 within HSCs successfully reproduced the mature lymphoid malignancies and pre-malignant status [33, 62-65], whereas the identical oncogenes expressed within B cells failed to develop leukemia or lymphoma in mice. These studies indicate that functional alterations in HSCs efficiently lead to the development of mature lymphoid malignancies, and can support the hypothesis that mature lymphoid malignancies may be initiated by the aberrant pre-leukemic HSCs (Fig. 3).

The novel lymphoma developmental model may not be applicable to all lymphoma cases. This field is still developing and there are many questions to be answered; however, compelling evidence has presented the possibility that HSPCs can contribute to the pathogenesis of mature lymphoid malignancies in a similar manner as myeloid malignancies. Further studies will clarify the precise molecular mechanisms through which the pre-leukemic HSCs play a central role in the stepwise malignant transformation process of mature lymphoid malignancies.

Acknowledgments We thank the members of the SyStemAge project for the helpful discussion. This study was supported in part by a Grant-in-Aid from the ministry of education, culture, sports, science and technology of Japan (to Y.K.) and a Grant-in-Aid from KANAE foundation (to Y.K.). This study was also supported in part by a Grantin-Aid for Scientific Research on Innovative Areas "Stem Cell Aging and Disease" from ministry of education, culture, sports, science and technology of Japan (to T.M.).

Conflict of interest The authors have no conflicts of interest to declare.

\section{References}

1. Ding L, Ley TJ, Larson DE, Miller CA, Koboldt DC, Welch JS, et al. Clonal evolution in relapsed acute myeloid leukaemia revealed by whole-genome sequencing. Nature. 2012;481(7382):506-10.

2. Walter MJ, Shen D, Ding L, Shao J, Koboldt DC, Chen K, et al. Clonal architecture of secondary acute myeloid leukemia. N Engl J Med. 2012;366(12):1090-8.

3. Yoshida K, Sanada M, Shiraishi Y, Nowak D, Nagata Y, Yamamoto R, et al. Frequent pathway mutations of splicing machinery in myelodysplasia. Nature. 2011;478(7367):64-9.

4. Wang L, Lawrence MS, Wan Y, Stojanov P, Sougnez C, Stevenson K, et al. SF3B1 and other novel cancer genes in chronic lymphocytic leukemia. N Engl J Med. 2011;365(26):2497-506.

5. Puente XS, Pinyol M, Quesada V, Conde L, Ordonez GR, Villamor $\mathrm{N}$, et al. Whole-genome sequencing identifies recurrent mutations in chronic lymphocytic leukaemia. Nature. 2011;475(7354):101-5.

6. Quesada V, Conde L, Villamor N, Ordonez GR, Jares P, Bassaganyas $\mathrm{L}$, et al. Exome sequencing identifies recurrent mutations of the splicing factor SF3B1 gene in chronic lymphocytic leukemia. Nat Genet. 2012;44(1):47-52.

7. Sakata-Yanagimoto M, Enami T, Yoshida K, Shiraishi Y, Ishii R, Miyake Y, et al. Somatic RHOA mutation in angioimmunoblastic T cell lymphoma. Nat Genet. 2014;46(2):171-5.

8. Morin RD, Mendez-Lago M, Mungall AJ, Goya R, Mungall KL, Corbett RD, et al. Frequent mutation of histone-modifying genes in non-Hodgkin lymphoma. Nature. 2011;476(7360):298-303.

9. Okosun J, Bodor C, Wang J, Araf S, Yang CY, Pan C, et al. Integrated genomic analysis identifies recurrent mutations and evolution patterns driving the initiation and progression of follicular lymphoma. Nat Genet. 2014;46(2):176-81.

10. Landau DA, Carter SL, Stojanov P, McKenna A, Stevenson K, Lawrence MS, et al. Evolution and impact of subclonal mutations in chronic lymphocytic leukemia. Cell. 2013;152(4):714-26.

11. Sanada M, Suzuki T, Shih LY, Otsu M, Kato M, Yamazaki S, et al. Gain-of-function of mutated C-CBL tumour suppressor in myeloid neoplasms. Nature. 2009;460(7257):904-8.

12. Kato M, Sanada M, Kato I, Sato Y, Takita J, Takeuchi K, et al. Frequent inactivation of A20 in B-cell lymphomas. Nature. 2009;459(7247):712-6.

13. Morin RD, Johnson NA, Severson TM, Mungall AJ, An J, Goya $\mathrm{R}$, et al. Somatic mutations altering EZH2 (Tyr641) in follicular 
and diffuse large B-cell lymphomas of germinal-center origin. Nat Genet. 2010;42(2):181-5.

14. Pasqualucci L, Dominguez-Sola D, Chiarenza A, Fabbri G, Grunn A, Trifonov V, et al. Inactivating mutations of acetyltransferase genes in B-cell lymphoma. Nature. 2011;471(7337):189-95.

15. Lenz G, Davis RE, Ngo VN, Lam L, George TC, Wright GW, et al. Oncogenic CARD11 mutations in human diffuse large B cell lymphoma. Science. 2008;319(5870):1676-9.

16. Palomero T, Couronne L, Khiabanian H, Kim MY, Ambesi-Impiombato A, Perez-Garcia A, et al. Recurrent mutations in epigenetic regulators, RHOA and FYN kinase in peripheral $\mathrm{T}$ cell lymphomas. Nat Genet. 2014;46(2):166-70.

17. Oricchio E, Nanjangud G, Wolfe AL, Schatz JH, Mavrakis KJ, Jiang M, et al. The Eph-receptor A7 is a soluble tumor suppressor for follicular lymphoma. Cell. 2011;147(3):554-64.

18. Lemonnier F, Couronne L, Parrens M, Jais JP, Travert M, Lamant $\mathrm{L}$, et al. Recurrent TET2 mutations in peripheral T-cell lymphomas correlate with TFH-like features and adverse clinical parameters. Blood. 2012;120(7):1466-9.

19. Cairns RA, Iqbal J, Lemonnier F, Kucuk C, de Leval L, Jais JP, et al. IDH2 mutations are frequent in angioimmunoblastic T-cell lymphoma. Blood. 2012;119(8):1901-3.

20. Rossi DJ, Jamieson CH, Weissman IL. Stems cells and the pathways to aging and cancer. Cell. 2008;132(4):681-96.

21. Miyamoto T, Weissman IL, Akashi K. AML1/ETO-expressing nonleukemic stem cells in acute myelogenous leukemia with 8;21 chromosomal translocation. Proc Natl Acad Sci USA. 2000;97(13):7521-6.

22. Miyamoto T, Nagafuji K, Akashi K, Harada M, Kyo T, Akashi T, et al. Persistence of multipotent progenitors expressing AML1/ ETO transcripts in long-term remission patients with $\mathrm{t}(8 ; 21)$ acute myelogenous leukemia. Blood. 1996;87(11):4789-96.

23. Shima T, Miyamoto T, Kikushige Y, Yuda J, Tochigi T, Yoshimoto $\mathrm{G}$, et al. The ordered acquisition of Class II and Class I mutations directs formation of human $\mathrm{t}(8 ; 21)$ acute myelogenous leukemia stem cell. Exp Hematol. 2014.

24. Jan M, Snyder TM, Corces-Zimmerman MR, Vyas P, Weissman IL, Quake SR, et al. Clonal evolution of preleukemic hematopoietic stem cells precedes human acute myeloid leukemia. Sci Transl Med. 2012;4(149):149ra18.

25. Shlush LI, Zandi S, Mitchell A, Chen WC, Brandwein JM, Gupta $\mathrm{V}$, et al. Identification of pre-leukaemic haematopoietic stem cells in acute leukaemia. Nature. 2014;506(7488):328-33.

26. Welch JS, Ley TJ, Link DC, Miller CA, Larson DE, Koboldt DC, et al. The origin and evolution of mutations in acute myeloid leukemia. Cell. 2012;150(2):264-78.

27. Walter MJ, Ding L, Shen D, Shao J, Grillot M, McLellan M, et al. Recurrent DNMT3A mutations in patients with myelodysplastic syndromes. Leukemia. 2011;25(7):1153-8.

28. Kikushige Y, Ishikawa F, Miyamoto T, Shima T, Urata S, Yoshimoto G, et al. Self-renewing hematopoietic stem cell is the primary target in pathogenesis of human chronic lymphocytic leukemia. Cancer Cell. 2011;20(2):246-59.

29. Kikushige Y, Miyamoto T. Hematopoietic stem cell aging and chronic lymphocytic leukemia pathogenesis. Int J Hematol. 2014;100(4):335-40.

30. Quivoron C, Couronne L, Della Valle V, Lopez CK, Plo I, Wagner-Ballon $\mathrm{O}$, et al. TET2 inactivation results in pleiotropic hematopoietic abnormalities in mouse and is a recurrent event during human lymphomagenesis. Cancer Cell. 2011;20(1):25-38.

31. Couronne L, Bastard C, Bernard OA. TET2 and DNMT3A mutations in human T-cell lymphoma. $\mathrm{N}$ Engl $\mathrm{J}$ Med. 2012;366(1):95-6.

32. Weigert $\mathrm{O}$, Weinstock DM. The evolving contribution of hematopoietic progenitor cells to lymphomagenesis. Blood. 2012;120(13):2553-61.
33. Chung SS, Kim E, Park JH, Chung YR, Lito P, Teruya-Feldstein $\mathrm{J}$, et al. Hematopoietic stem cell origin of BRAFV600E mutations in hairy cell leukemia. Sci Transl Med. 2014;6(238):238ra71.

34. Chiorazzi N, Rai KR, Ferrarini M. Chronic lymphocytic leukemia. N Engl J Med. 2005;352(8):804-15.

35. Zenz T, Mertens D, Kuppers R, Dohner H, Stilgenbauer S. From pathogenesis to treatment of chronic lymphocytic leukaemia. Nat Rev Cancer. 2011;10(1):37-50.

36. Stevenson FK, Caligaris-Cappio F. Chronic lymphocytic leukemia: revelations from the B-cell receptor. Blood. 2004;103(12):4389-95.

37. Caligaris-Cappio F, Ghia P. Novel insights in chronic lymphocytic leukemia: are we getting closer to understanding the pathogenesis of the disease? J Clin Oncol. 2008;26(27):4497-503.

38. Hamblin TJ, Davis Z, Gardiner A, Oscier DG, Stevenson FK. Unmutated $\mathrm{Ig} \mathrm{V}(\mathrm{H})$ genes are associated with a more aggressive form of chronic lymphocytic leukemia. Blood. 1999;94(6):1848-54.

39. Seifert M, Sellmann L, Bloehdorn J, Wein F, Stilgenbauer S, Durig J, et al. Cellular origin and pathophysiology of chronic lymphocytic leukemia. J Exp Med. 2012;209(12):2183-98.

40. Sanchez ML, Almeida J, Gonzalez D, Gonzalez M, GarciaMarcos MA, Balanzategui A, et al. Incidence and clinicobiologic characteristics of leukemic B-cell chronic lymphoproliferative disorders with more than one B-cell clone. Blood. 2003;102(8):2994-3002.

41. Landgren O, Albitar M, Ma W, Abbasi F, Hayes RB, Ghia P, et al. B-cell clones as early markers for chronic lymphocytic leukemia. N Engl J Med. 2009;360(7):659-67.

42. Marti GE, Rawstron AC, Ghia P, Hillmen P, Houlston RS, Kay N, et al. Diagnostic criteria for monoclonal B-cell lymphocytosis. $\mathrm{Br}$ J Haematol. 2005;130(3):325-32.

43. Nieto WG, Almeida J, Romero A, Teodosio C, Lopez A, Henriques AF, et al. Increased frequency (12\%) of circulating chronic lymphocytic leukemia-like B-cell clones in healthy subjects using a highly sensitive multicolor flow cytometry approach. Blood. 2009;114(1):33-7.

44. Dagklis A, Fazi C, Sala C, Cantarelli V, Scielzo C, Massacane R, et al. The immunoglobulin gene repertoire of low-count chronic lymphocytic leukemia (CLL)-like monoclonal B lymphocytosis is different from CLL: diagnostic implications for clinical monitoring. Blood. 2009;114(1):26-32.

45. Lanasa MC, Allgood SD, Volkheimer AD, Gockerman JP, Whitesides JF, Goodman BK, et al. Single-cell analysis reveals oligoclonality among 'low-count' monoclonal B-cell lymphocytosis. Leukemia. 2010;24(1):133-40.

46. Shim YK, Rachel JM, Ghia P, Boren J, Abbasi F, Dagklis A, et al. Monoclonal B-cell lymphocytosis in healthy blood donors: an unexpectedly common finding. Blood. 2014;123(9):1319-26.

47. Rawstron AC, Bennett FL, O'Connor SJ, Kwok M, Fenton JA, Plummer M, et al. Monoclonal B-cell lymphocytosis and chronic lymphocytic leukemia. N Engl J Med. 2008;359(6):575-83.

48. Marti G, Abbasi F, Raveche E, Rawstron AC, Ghia P, Aurran T, et al. Overview of monoclonal B-cell lymphocytosis. Br J Haematol. 2007;139(5):701-8.

49. Shanafelt TD, Kay NE, Rabe KG, Call TG, Zent CS, Maddocks $\mathrm{K}$, et al. Brief report: natural history of individuals with clinically recognized monoclonal B-cell lymphocytosis compared with patients with Rai 0 chronic lymphocytic leukemia. J Clin Oncol. 2009;27(24):3959-63.

50. Ghiotto F, Fais F, Valetto A, Albesiano E, Hashimoto S, Dono $\mathrm{M}$, et al. Remarkably similar antigen receptors among a subset of patients with chronic lymphocytic leukemia. J Clin Invest. 2004;113(7):1008-16.

51. Messmer BT, Albesiano E, Efremov DG, Ghiotto F, Allen SL, Kolitz J, et al. Multiple distinct sets of stereotyped antigen 
receptors indicate a role for antigen in promoting chronic lymphocytic leukemia. J Exp Med. 2004;200(4):519-25.

52. Tobin G, Thunberg U, Karlsson K, Murray F, Laurell A, Willander K, et al. Subsets with restricted immunoglobulin gene rearrangement features indicate a role for antigen selection in the development of chronic lymphocytic leukemia. Blood. 2004;104(9):2879-85.

53. Widhopf GF 2nd, Rassenti LZ, Toy TL, Gribben JG, Wierda WG, Kipps TJ. Chronic lymphocytic leukemia B cells of more than $1 \%$ of patients express virtually identical immunoglobulins. Blood. 2004;104(8):2499-504.

54. Sthoeger ZM, Wakai M, Tse DB, Vinciguerra VP, Allen SL, Budman DR, et al. Production of autoantibodies by CD5-expressing B lymphocytes from patients with chronic lymphocytic leukemia. J Exp Med. 1989;169(1):255-68.

55. Broker BM, Klajman A, Youinou P, Jouquan J, Worman CP, Murphy J, et al. Chronic lymphocytic leukemic (CLL) cells secrete multispecific autoantibodies. J Autoimmun. 1988;1(5):469-81.

56. Borche L, Lim A, Binet JL, Dighiero G. Evidence that chronic lymphocytic leukemia B lymphocytes are frequently committed to production of natural autoantibodies. Blood. 1990;76(3):562-9.

57. Herve M, Xu K, Ng YS, Wardemann H, Albesiano E, Messmer BT, et al. Unmutated and mutated chronic lymphocytic leukemias derive from self-reactive $\mathrm{B}$ cell precursors despite expressing different antibody reactivity. J Clin Invest. 2005;115(6):1636-43.

58. Bonnet D, Dick JE. Human acute myeloid leukemia is organized as a hierarchy that originates from a primitive hematopoietic cell. Nat Med. 1997;3(7):730-7.
59. Akashi K, He X, Chen J, Iwasaki H, Niu C, Steenhard B, et al. Transcriptional accessibility for genes of multiple tissues and hematopoietic lineages is hierarchically controlled during early hematopoiesis. Blood. 2003;101(2):383-9.

60. Miyamoto T, Iwasaki H, Reizis B, Ye M, Graf T, Weissman IL, et al. Myeloid or lymphoid promiscuity as a critical step in hematopoietic lineage commitment. Dev Cell. 2002;3(1):137-47.

61. Damm F, Mylonas E, Cosson A, Yoshida K, Della Valle V, Mouly $\mathrm{E}$, et al. Acquired initiating mutations in early hematopoietic cells of CLL patients. Cancer Discov. 2014;4(9):1088-101.

62. Vicente-Duenas C, Fontan L, Gonzalez-Herrero I, RomeroCamarero I, Segura V, Aznar MA, et al. Expression of MALT1 oncogene in hematopoietic stem/progenitor cells recapitulates the pathogenesis of human lymphoma in mice. Proc Natl Acad Sci USA. 2012;109(26):10534-9.

63. Vicente-Duenas C, Romero-Camarero I, Gonzalez-Herrero I, Alonso-Escudero E, Abollo-Jimenez F, Jiang X, et al. A novel molecular mechanism involved in multiple myeloma development revealed by targeting MafB to haematopoietic progenitors. EMBO J. 2012;31(18):3704-17.

64. Romero-Camarero I, Jiang X, Natkunam Y, Lu X, Vicente-Duenas C, Gonzalez-Herrero I, et al. Germinal centre protein HGAL promotes lymphoid hyperplasia and amyloidosis via BCR-mediated Syk activation. Nat Commun. 2013;4:1338.

65. Green MR, Vicente-Duenas C, Romero-Camarero I, Long Liu C, Dai B, Gonzalez-Herrero I, et al. Transient expression of Bcl6 is sufficient for oncogenic function and induction of mature B-cell lymphoma. Nat Commun. 2014;5:3904. 